\title{
Are Costs of Capital Necessarily Constant over Time and across States of Nature?
}

\author{
Some Remarks on the Debate on 'WACC is not quite right' \\ Daniela Lorenz, Lutz Kruschwitz, and Andreas Löffler ${ }^{1}$ \\ Freie Universität Berlin, School of Economics and Business.
}

\begin{abstract}
Miller (2009a) opened a debate in this journal on the correct determination of weighted average costs of capital (WACC). So far Bade (2009), Pierru (2009a), Lobe (2009) as well as Keef et al. (2012) have contributed to this debate. Even though they discuss the same, rather simple valuation problem, the dispute cannot be considered resolved. Whilst they agree that Miller erroneously assumed constant leverage ratios, the center of discussion is now placed on the question whether or not cost of capital is constant over time when leverage changes and interest paid is not tax deductible. In particular, Keef et al. (2012) demand time-invariant WACC and criticize Bade (2009) and Pierru (2009a) for allowing WACC to change over time. The aim of this paper is twofold. Firstly, we show that the arguments of Keef et al. (2012) are flawed and their criticism of Bade (2009) and Pierru (2009a) is thus unfounded. Keef et al. (2012) are wrong to ignore that not only financial risk but also operational risk can change over time. Secondly, we provide evidence that cost of capital can also be dependent on the future state of nature. So far this fact has been neglected by all contributors to this debate and becomes obvious only if state-dependent cash flow realizations, not only their expected values, are considered as well.
\end{abstract}

$U R L$ :

www .wiwiss.fu-berlin.de/fachbereich/bwl/pruefungs-steuerlehre/loeffler/index.html (Daniela Lorenz, Lutz Kruschwitz, and Andreas Löffler)

Preprint submitted to Quarterly Review of Economics and Finance

August 1, 2015 
Keywords: valuation, discounted cash flow, cost of capital

JEL: G30, G31, G32

\section{Introduction}

Recently this journal hosted a heated debate on how the weighted average cost of capital is to be interpreted and how it should advantageously be determined. Miller (2009a) argued that a simple linear interpolation of cost of

5 equity and cost of debt leads to wrong valuation results. To prove his claim he presented an extensive example.

Bade (2009) as well as Pierru (2009a) object to Miller vehemently and point out that his valuation approach contains an error. Miller (2009a) wrongly assumed that the leverage ratio is constant over time. Based on the same example used by Miller (2009a) and disregarding taxes, Bade (2009) and Pierru (2009a) show that this leverage ratio does change over time and that hence Miller/s result cannot be upheld. In particular, they illustrate that the weighted average cost of capital (WACC) must increase over time when cost of levered equity and of debt remain constant and Miller's repayment schedules apply, i.e. leverage declines.

15 Thus, WACC should be time-dependent. Alternatively, Pierru (2009a) adjusts the repayment schedules assumed in Miller's example in such a manner that the debt ratio as well as WACC remain constant. 1 In his reply Miller (2009b) admits that his original repayment schedule is not compatible with a constant debt

\footnotetext{
${ }^{1}$ Similarly, Lobe (2009) presents the identical two alternatives for proving the correctness of the traditional WACC. The latter alternative was heavily criticized by Tanha and Foroutan (2013) who base their argumentation on the distinction between the so-called Total Cash Flow approach that considers the tax shield in the numerator (see, e.g., Kruschwitz and Löfller 2006 section 2.4.2)) and the WACC approach that accounts for the tax shield in the denominator. They state that Pierru (2009a), Bade (2009), and Miller (2009a) "failed to answer Miller's question correctly because they did not consider this fact that they were assuming one description of the cash flow while using another formula for WACC which assumes the other description of the cash flow" (Tanha and Foroutan 2013, page 2083). However, the distinction between both approaches (i.e. cash flow descriptions and WACC formulas) is by no means suitable to demonstrate weaknesses in the afore-mentioned papers
} 
ratio and additionally proposes another three (non-self-amortizing) repayment schedules. ${ }^{2}$

Recently Keef et al. (2012) have attempted to summarize the discussion and place it in a wider context. From their point of view, Bade (2009) as well as Pierru (2009a) have made another hitherto hidden mistake and therefore the question raised by Miller remains unsolved. Whilst Keef et al. (2012) agree and Pierru (2009a) "incorrectly conclude that the annual WACC increases over time" ${ }^{3}$ Instead they argue that in a world without taxes WACC is independent of leverage and should thus be constant over time. They believe that Bade (2009) and Pierru (2009a) erroneously "assume, for convenience, that the required rate so of return on levered equity is independent of leverage" 4 Analogously, this critique applies to Lobe (2009) whose argumentation is in line with Bade (2009) and Pierru (2009a).

The aim of our study is twofold. Firstly, we are convinced that the arguments of Keef et al. (2012) supporting time-independency of WACC are flawed. Whilst Keef et al. (2012) solely focus on changes in financial risk (resulting from changes in leverage) they neglect the fact that operational risk can change over time, too. In particular, we show that even regardless of taxes WACC can indeed be time-dependent and that the criticism voiced by Keef et al. (2012) is thus ill-founded.

that all assume a world without taxes where both approaches inevitably coincide.

${ }^{2}$ Also, in his reply Miller claims that the only relevant costs of capital and debt ratios are those that exist at $t=0$, the time the project is accepted and financed. However, the project's present value is generally calculated according to $\frac{E\left[\widetilde{C F}_{1}\right]}{1+W A C C_{0}}+\frac{E\left[\widetilde{C F}_{2}\right]}{\left(1+W A C C_{0}\right)\left(1+W A C C_{1}\right)}+\ldots+$ $\frac{E\left[\widetilde{C F}_{n}\right]}{\left(1+W A C C_{0}\right) \ldots\left(1+W A C C_{n-1}\right)}$. Thus, apart from the special case of constant WACC it is indeed indispensable for the capital budgeting decision in $t=0$ to calculate $W A C C_{t}$ for every future period $t=0,1, \ldots, n-1$ for which future costs of equity, costs of debt and future debt ratios apply. Similarly, Pierru (2009b) argues that Miller's argumentation is unsubstantiated and that the resulting discounting procedure might violate essential consistency properties.

3 Keef et al. (2012), page 441.

$4 \overline{\text { Keef et al. }}(2012)$, page 441. 
Secondly, we want to draw the reader's attention to another issue that has not been discussed in any of the previously cited papers with sufficient care. Remarkably, all contributors to this debate have ignored the way risk affects cash flows. If, however, one properly accounts for the fact that cash flows are state-contingent, we show that cost of capital does not necessarily have to be

45 independent of future states of nature. This, however, is the implicit assumption in all previously cited papers.

\section{Time-dependency of Cost of Capital}

The focus of this section is to analyze the time-dependency of WACC from a theoretical point of view. To illustrate our argumentation and improve its comparability to prior papers in this field we refer to the same example introduced by Miller (2009a) and taken up by Bade (2009), Pierru (2009a), Lobe (2009) as well as Keef et al. (2012). Table 1 in the appendix summarizes the setting. Table 2 reflects the proposed cost of capital that differs according to whether or not WACC has to be constant over time. In line with the proposal 55 of Bade (2009), Pierru (2009a), and Lobe (2009), we show that WACC can indeed change over time and the criticism of Keef et al. (2012) is thus unfounded. This holds true even in absence of taxes - a setting in which WACC equals the cost of unlevered equity $r_{e}^{U}$ and is thus independent of leverage. However, it is wrong to assume that $r_{e}^{U}$ (a measure for the operational risk to which a firm is exposed) has to be constant over time. Note, that in line with all other papers contributing to this discussion we do not explicitly account for interest rate risk. However, the modeling of interest rate changes over time would affect costs of capital which again supports time-varying WACC.

In contrast to Bade (2009), Pierru (2009a), and Lobe (2009) Keef et al. 65 (2012) support the idea of constant WACC over time and base their argumentation on the following relationship between the cost of levered equity $r_{e}^{L}$, cost of unlevered equity $r_{e}^{U}$, cost of debt $r_{b}$ as well as leverage $L$

$$
r_{e}^{L}=r_{e}^{U}+\left(r_{e}^{U}-r_{b}\right) \times L
$$


This relationship is derived from the combination of two theorems that we discuss separately in the following.

1. The first theorem necessary to derive Equation (1) is an adjustment formula that appropriately describes the relationship between weighted average cost of capital WACC and cost of unlevered equity $r_{e}^{U}$. In this respect Keef et al. (2012) refer to the seminal works of Modigliani and Miller (1963) as well as Miles and Ezzell (1980) from which such adjustment formulas can be inferred. In their most general form they read as follows:

$$
\begin{gathered}
W A C C=\left(1-\tau \times l_{0}\right) \times r_{e}^{U} \\
W A C C_{t}=\left(1+r_{e, t}^{U}\right)\left(1-\frac{\tau \times r_{f}}{1+r_{f}} \times l_{t}\right)-1
\end{gathered}
$$

They are known as the Modigliani-Miller adjustment formula (2a) and the Miles-Ezzell adjustment formula (2b), respectively. In these equations $l$ denotes the leverage ratio whereas $L$ in Equation (1) stands for the debt equity ratio. Both measures of leverage can easily be converted into one another. For the risk-free rate we use the symbol $r_{f}$. Obviously, if we assume the absence of taxes, $\tau=0$, both equations coincide and arrive at the result that WACC equals the cost of unlevered equity. Nevertheless, it is crucial to distinguish clearly between both formulas because they are based on different assumptions and only in case of the Miles-Ezzell adjustment formula $(2 \mathrm{~b}$ ) do the cost of capital and the leverage ratio carry time subscripts and are thus time-dependent. In particular, the ModiglianiMiller adjustment formula (2a) can only be derived if one assumes that the amount of debt $D_{t}$ does not change over time (the firm never redeems its debt) and that the firm's time horizon is either infinite or just one period. Both assumptions are clearly not met in the example at the center of the debate (see Table 1). By contrast, the Miles-Ezzell adjustment for- 
mula assumes deterministic but not necessarily constant leverage ratio: as well as deterministic but not necessarily constant cost of capital. Thus, the Miles-Ezzell adjustment formula is applicable to the example in Table 1 without contradiction. In a world without taxes, $\tau=0$, it simplifies to

$$
W A C C_{t}=r_{e, t}^{U} .
$$

Obviously, weighted average costs of capital can indeed be time-dependent - a fact that is neglected by Keef et al.

2. In order to derive Equation (1), one also has to use a formula that determines WACC as the average of the cost of levered equity and debt weighted by equity and debt ratio, respectively,

$$
W A C C_{t}=\left(1-l_{t}\right) \times r_{e, t}^{L}+l_{t} \times(1-\tau) \times r_{b, t} .
$$

Equation (4) can be found in almost every finance textbook and is thus known as the textbook formula. In order to apply this formula significantly fewer assumptions are involved compared to the adjustment formulas. Rather, it is possible to show that the textbook formula is a trivial conclusion of the cost of capital definition and holds even if the expected returns are random variables ${ }^{6}$ Note, however, that it is possible that these variables change over time 7

Against this background we do not understand why Keef et al. (2012) argue that WACC should always be constant over time. According to our considerations above, neither Equation (3) nor Equation (4) requires the assumption of

\footnotetext{
${ }^{5}$ Whilst Miles and Ezzell derive their formula only for the case of a constant leverage ratio, it has been proven that the assumption of a deterministic but time-variant leverage ratio is sufficient to derive the formula 2b). See, e.g., (Kruschwitz and Löffler, 2006 section 2.4.4). In this respect (Pierru 2009a, p. 1220) is mistaken in believing that "a constant WACC implicitly requires the debt ratio to also remain constant".

${ }^{6}$ See, e.g., (Kruschwitz and Löffler 2006 section 2.4.3). The fact that cost of capital may be random variables, i.e., are state-dependent, is not acknowledged in any paper involved in the debate. We focus on this issue in the next section.

${ }^{7}$ See, e.g., Lobe (2009).
} 
constant WACC. The claim of Keef et al. (2012) is thus unfounded and unsubstantiated by theory.

For $\tau=0$ equalizing both equations and rearranging yields

$$
r_{e, t}^{L}=r_{e, t}^{U}+\left(r_{e, t}^{U}-r_{b, t}\right) \times L_{t} .
$$

A comparison to Equation (1) reveals that cost of levered equity $r_{e}^{L}$ can also be time-variant and positively depend on the debt equity ratio $L$ which itself can be time-dependent 8 This relates directly to another criticism leveled at Bade (2009) and Pierru (2009a) that is expressed by Keef et al. (2012) and that is, we believe, also unfounded. Specifically, Keef et al. (2012) claim "their error is to assume, for convenience, that the required rate of return on levered equity $r_{e}^{L}$ is independent of leverage." They refer to Equation (1) in order to underpin this statement. We agree that this equation clearly indicates that cost of equity are higher the more a firm is exposed to financial risk, i.e,. the greater its leverage. Since the leverage ratio in Table 1 decreases over time, Keef et al. (2012) conclude that $r_{e}^{L}$ should then also decrease which, as they claim, is ignored by Bade (2009) and Pierru (2009a). However, this line of argumentation neglects the fact that according to Equation (5) cost of levered equity $r_{e}^{L}$ are not only driven by financial risk (leverage $L_{t}$ ) but also by operational risk (measured by cost of unlevered equity $r_{e, t}^{U}$ ) which itself can change over time, see, e.g., Lobe (2009) . In the (albeit unrealistic but at least consistent) example of Bade (2009) and Pierru (2009a) the effect of an increasing operational risk and that of a decreasing financial risk perfectly compensate for each other, resulting in cost of levered equity $r_{e}^{L}$ amounting to $12 \%$ at every future point of time. By taking 135 a closer look at the numbers in Table 2 one must recognize that the relation (5) is fulfilled at every single future date in the example of Bade (2009) and Pierru (2009a) which was wrongly doubted by Keef et al. (2012) 9

n Finally, we wish to point out that the cost of capital proposed by Keef

${ }^{8}$ See, e.g., Buus $(2015)$.

${ }^{5}$ At date $t=4$, for example, $r_{e, 4}^{\square}$ amounts to $10.60 \%$, costs of debt $r_{b, 4}$ are $6 \%$ and debt equity ratio amounts to $L_{4}=\frac{27.9}{91.714}$. Plugging these numbers into Equation (5) yields 
et al. (2012) (see Table 2) - in contrast to those proposed by Bade (2009),

140 Pierru (2009a), and Lobe (2009) - are inconsistent with the underlying setting described in Table 1. The market value of equity $E_{t}$ must equal the sum of future dividends discounted by the cost of levered equity,

$$
E_{t}=\sum_{s=t+1}^{T} \frac{E\left[\widetilde{C F}_{e, s}\right]}{\left(1+r_{e, t}^{L}\right) \cdots\left(1+r_{e, s-1}^{L}\right)} .
$$

This basic relationship is however not fulfilled by Keef et al. (2012). Using the proposed cost of levered equity does not yield the given equity values and leverage ratios.

\section{State-Dependency of Cost of Capital}

Whilst the previous section focuses on time-dependency of weighted average cost of capital, we now turn to the question of whether they are necessarily independent of the future states of nature. This assumption is implicitly made by all contributions that are involved in the debate. For simplicity and comparability we take up another example that is already provided by Keef et al. (2012): we consider a firm with a lifespan of two periods that carries out a single investment project. The (expected) cash flows are -260 in $t=0,160$ in $t=1$ and 160 in $t=2$. In order to clarify what we want to discuss, we draw a binomial tree, see figure 1. This tree does not show the expected cash flows but their state-contingent realizations. In this regard, it goes beyond the examples of Miller, Bade, Pierru as well as Keef et al. The (subjective) probability for any path of the tree is $50 \%$. This makes it fairly easy to calculate the expected cash flows. They amount to 160 in $t=1$ and $t=2$. There are no taxes.

We assume that claims on said cash flows are traded in a market that is both complete and arbitrage-free. Such an assumption is far from unusual in the theory of finance. It is a standard assumption that, for example, is often

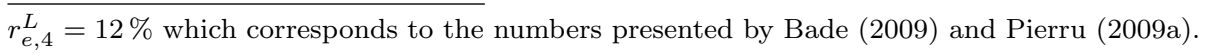
See Table 2 
Figure 1: A first example with expected cash flows of 160 at $t=1$ and 160 at $t=2$.

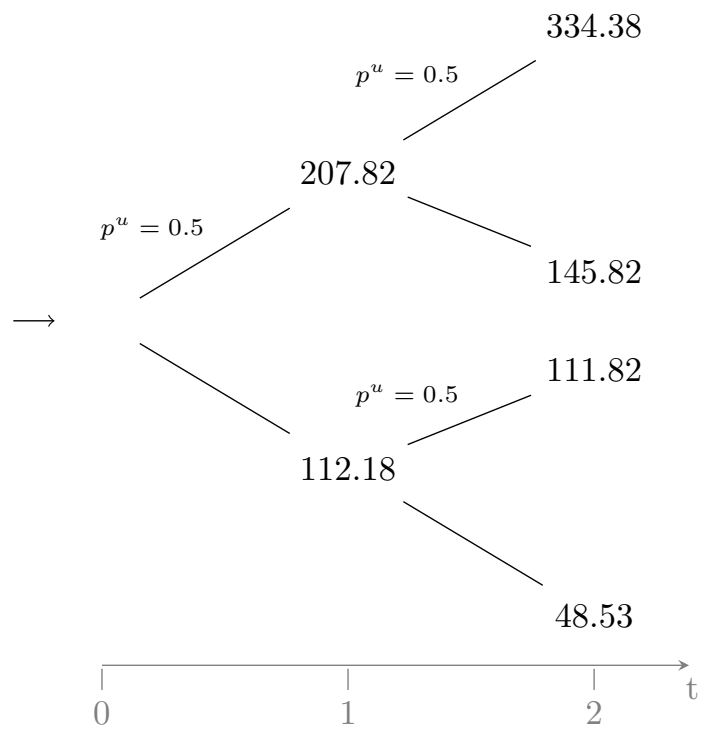

used in option pricing theory. If the assumption is made as described, then the fundamental theorem of asset pricing applies 10 The theorem states that there exists a risk-neutral probability with which one can easily evaluate any risky asset. Let us assume that the risk-neutral probabilities for the up and down movements of the binomial tree are given with $q^{u}=40 \%$ and $q^{d}=1-q^{u}=60 \%$. Finally, we want to assume that the risk-free rate amounts to $r_{f}=6 \%$. Based on this information, the values of the company at $t=0$ and $t=1$ can easily be calculated. We obtain at $t=1$ in the case of an upward movement

$$
V_{1}^{u}=\frac{E_{Q}\left[\widetilde{C F}_{2}^{u}\right]}{1+r_{f}}=\frac{0.4 \times 334.38+0.6 \times 145.82}{1.06}=208.72
$$

and in the case of a downward movement

$$
V_{1}^{d}=\frac{E_{Q}\left[\widetilde{C F}_{2}^{d}\right]}{1+r_{f}}=\frac{0.4 \times 111.82+0.6 \times 48.53}{1.06}=69.46,
$$

\footnotetext{
${ }^{10}$ See Harrison and Kreps $(1979)$.
} 
and at $t=0$

$$
V_{0}=\frac{0.4 \times(207.82+208.72)+0.6 \times(112.18+69.46)}{1.06}=260 .
$$

Using the subjective probability measure this corresponds to the following weighted average costs of capital:

$$
\begin{aligned}
W A C C_{1}^{u} & =\frac{0.5 \times 334.83+0.5 \times 145.82}{208.72}-1=15.03 \% \\
W A C C_{1}^{d} & =\frac{0.5 \times 111.28+0.5 \times 48.53}{69.46}-1=15.03 \% \\
W A C C_{0} & =\frac{0.5 \times(207.82+208.72)+0.5 \times(112.18+69.49)}{260}-1=15.03 \% .
\end{aligned}
$$

As we can see, in this example weighted average costs of capital are constant not only over time but also across states. This corresponds to the numbers provided by Keef et al. (2012)

In a second step we now consider another binomial tree shown in figure 2. Again the expected cash flows amount to 160 at each future point of time. Using the same probabilities as before and again assuming a riskless rate of $6 \%$, we obtain $V_{0}=260$ for the value of the company, a result which in no way differs from the earlier case. However, one obtains completely different weighted average costs of capital than before. By performing the required calculations we obtain

$$
W A C C_{1}^{u}=16.04 \% \quad W A C C_{1}^{d}=7.40 \% \quad W A C C_{0}=15.81 \%
$$

In this example, weighted costs of capital are obviously not only dependent on time, they also vary across states. In this case fundamental theorems like the adjustment formulas described above are no longer applicable.

What can we learn from these two examples? Whilst the general setting of both examples is identical (particularly the expected cash flows), only the state-dependent realizations of the cash flows differ. None of the authors who have previously contributed to the subject in this journal have been able to distinguish the two cases described by figures 1 and 2 , respectively. They only 
Figure 2: A second example with expected cash flows of 160 at $t=1$ and 160 at $t=2$.

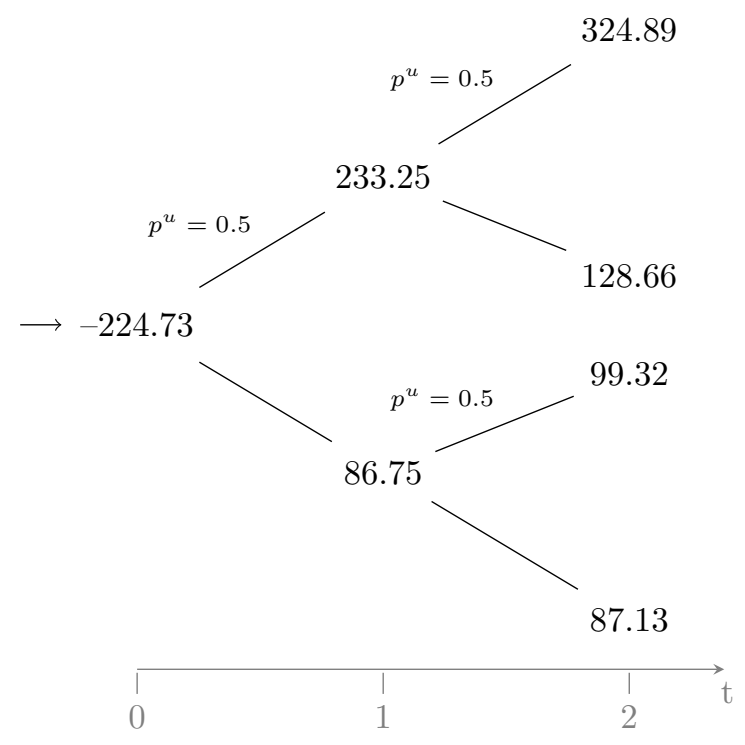

focus on expected cash flows and do not consider the underlying probability distribution of their realizations. But that is exactly what is needed when it comes to determining the appropriate cost of capital.

The cost of capital concept is surely essential to the theory of finance. Surprisingly, clear and unambiguous definitions of the term are few and far between in the relevant literature. In a multi-period model, the terms "(expected) return", "cost of capital" and "discount factor" do not necessarily denote the same concept ${ }^{11}$ Our examples reveal that there may be not only one but several expected returns and that costs of capital are not necessarily state-independent. It is not sufficient to deal with expected cash flows. Rather, one must examine the stochastic structure of those payments ${ }^{12}$ He who ignores all this behaves like someone who keeps his ears closed while the orchestra is playing because he believes that he can appreciate the music by merely looking at the musicians.

\footnotetext{
${ }^{11}$ See $($ Kruschwitz and Löffler, 2006, pp 22 ff.) for more details.

${ }^{12}$ For more details, see again (Kruschwitz and Löffler 2006, pp 33 ff.).
} 


\section{Summary}

205 of costs of capital, to which Bade (2009), Pierru (2009a), Lobe (2009) as well as Keef et al. (2012) have contributed. All these authors focus on a rather simple problem, namely the valuation of a firm with a finite life-time in the absence of taxes. One would expect this valuation problem to be an easy task, however the debate on this remains unresolved.

In this paper we scrutinize the study of Keef et al. that criticizes the solutions to the valuation problem provided by Bade (2009) and Pierru (2009a). In contrast to the latter, Keef et al. assume that weighted average costs of capital have to be constant over time and that the costs of levered equity necessarily have to decrease if leverage declines. We show that this is a possible but not mandatory assumption. In particular, if one takes into account that operational risk may increase over time, we have two opposing effects on costs of levered equity: a lower financial risk on the one hand and a higher operational risk on the other. Which effect dominates depends on the specific valuation environment. It is even possible that both opposing effects perfectly balance each other out, resulting in time-independent costs of levered equity, which is assumed by Bade (2009) and Pierru (2009a). Thus, the criticism raised by Keef et al. is unfounded.

Moreover, we discuss another issue that has not been studied with sufficient care in any of the previously cited papers. Whilst all authors assume that future cash flows are uncertain, no one specifies the cash flows' probability distribution. Instead they only concentrate on the expected value of future cash flows. We show that costs of capital may vary not only over time but also across the future states of nature, if one takes a closer look at the state-dependent cash 230 by many valuation theorists. 


\section{References}

Bade B. Comment on 'The weighted average cost of capital is not quite right'. The Quarterly Review of Economics and Finance 2009;49:1476-80.

235 Buus T. A general free cash flow theory of capital structure. Journal of Business Economics and Management 2015;16:675-95.

Harrison JM, Kreps DM. Martingales and arbitrage in multiperiod securities markets. Journal of Economic Theory 1979;20:381-408.

Keef SP, Khaled MS, Roush ML. A note resolving the debate on 'The weighted average cost of capital ist not quite right'. The Quarterly Review of Economics and Finance 2012;52:438-42.

Kruschwitz L, Löffler A. Discounted Cash Flow: A Theory of the Valuation of Firms. Chichester: John Wiley \& Sons, 2006.

Lobe S. Caveat WACC: Pitfalls in the use of the weighted average cost of capital. Corporate Ownership and Control 2009;6(3):45-52.

Miles JA, Ezzell JR. The weighted average cost of capital, perfect capital markets, and project life: A clarification. Journal of Financial and Quantitative Analysis 1980;15:719-30.

Miller RA. The weighted average cost of capital is not quite right. The Quarterly Review of Economics and Finance 2009a;49:128-38.

Miller RA. The weighted average cost of capital is not quite right: Reply to M. Pierru. The Quarterly Review of Economics and Finance 2009b;49:1213-8.

Modigliani F, Miller MH. Corporate income taxes and the cost of capital: A correction. American Economic Review 1963;53:433-43.

255 Pierru A. 'The weighted average cost of capital is not quite right': A comment. The Quarterly Review of Economics and Finance 2009a;49:1219-23. 
Pierru A. 'The weighted average cost of capital is not quite right': A rejoinder.

The Quarterly Review of Economics and Finance 2009b;49:1481-4.

Tanha FH, Foroutan M. How to get correct result from weighted average cost of capital (WACC) formula and avoid a common pitfall in calculating WACC: An analysis of Miller (2009) and Pierru's (2009) articles. African Journal of Business Management 2013;7(22):2079-85. 


\section{Appendix}

Table 1: Miller-Example

This table reports the market value of a firm $V_{t}$ carrying out a single investment project with total cash flow amounting to $C F_{t}$. For the leverage ratio the symbol $l_{t}$ is used. $E_{t}$ and $D_{t}$ denote market value of equity and debt, respectively. $C F_{e, t}$ and $C F_{b, t}$ are the amounts of cash that flow to equity and debt, respectively. Numbers are taken from (Bade 2009 Table 1, page 1478), (Pierru, 2009a Table 2, page 1222) and (Lobe 2009, Table 2, page 48), respectively.

\begin{tabular}{c|rrr|r|rrr}
\hline \hline$t$ & $V_{t}=E_{t}+D_{t}$ & $E_{t}$ & $D_{t}$ & $l_{t}=D_{t} / V_{t}$ & $C F_{t}$ & $C F_{e, t}$ & $C F_{b, t}$ \\
\hline 0 & 200.000 & 150.000 & 50.000 & $25.00 \%$ & -200.000 & -150.000 & -50.000 \\
1 & 182.753 & 137.805 & 44.948 & $24.60 \%$ & 38.247 & 30.195 & 8.052 \\
2 & 163.739 & 124.146 & 39.593 & $24.18 \%$ & 38.247 & 30.195 & 8.052 \\
3 & 142.765 & 108.848 & 33.917 & $23.76 \%$ & 38.247 & 30.195 & 8.052 \\
4 & 119.614 & 91.714 & 27.900 & $23.33 \%$ & 38.247 & 30.195 & 8.052 \\
5 & 94.047 & 72.524 & 21.523 & $22.88 \%$ & 38.247 & 30.195 & 8.052 \\
6 & 65.794 & 51.032 & 14.762 & $22.44 \%$ & 38.247 & 30.195 & 8.052 \\
7 & 34.556 & 26.960 & 7.596 & $21.98 \%$ & 38.247 & 30.195 & 8.052 \\
8 & 0.000 & 0.000 & 0.000 & & 38.247 & 30.195 & 8.052 \\
\hline
\end{tabular}


Table 2: Proposed Costs of Capital of the Miller Example

This table reports the costs of capital as proposed by Bade (2009)/Pierru (2009a)/Lobe (2009) and Keef et al. (2012). In case of Bade (2009)/Pierru (2009a)/Lobe (2009) the numbers for all points in time $t$ can directly be taken from their tables. By contrast, Keef et al. (2012) perform their calculation only for $t=4$ exemplarily, see (Keef et al. 2012, Table 4, Panel A and C, page 441). Applying the same rationale with regard to other dates yields the numbers in the last columns. Cost of levered equity is denoted by $r_{e, t}^{L}, r_{b, t}$ stand for costs of debt and $W A C C_{t}$ are the weighted average costs of capital that equal the costs of unlevered equity $r_{e, t}^{U}$ assuming absent taxes.

\begin{tabular}{|c|c|c|c|c|c|c|}
\hline \multirow[b]{2}{*}{$t$} & Bade & (2009)/Pierru & \multirow{2}{*}{$\begin{array}{l}\text { (2009a)/Lobe (2009) } \\
W A C C_{t}=r_{e, t}^{U}\end{array}$} & \multirow[b]{2}{*}{$r_{e, t}^{L}$} & \multicolumn{2}{|c|}{ Keef et al. (2012) } \\
\hline & $r_{e, t}^{L}$ & $r_{b, t}$ & & & $r_{b, t}$ & $W A C C_{t}=r_{e, t}^{U}$ \\
\hline 0 & $12 \%$ & $6 \%$ & $10.50 \%$ & $12.07 \%$ & $6 \%$ & $10.55 \%$ \\
\hline 1 & $12 \%$ & $6 \%$ & $10.52 \%$ & $12.04 \%$ & $6 \%$ & $10.55 \%$ \\
\hline 2 & $12 \%$ & $6 \%$ & $10.55 \%$ & $12.01 \%$ & $6 \%$ & $10.55 \%$ \\
\hline 3 & $12 \%$ & $6 \%$ & $10.57 \%$ & $11.97 \%$ & $6 \%$ & $10.55 \%$ \\
\hline 4 & $12 \%$ & $6 \%$ & $10.60 \%$ & $11.94 \%$ & $6 \%$ & $10.55 \%$ \\
\hline 5 & $12 \%$ & $6 \%$ & $10.63 \%$ & $11.90 \%$ & $6 \%$ & $10.55 \%$ \\
\hline 6 & $12 \%$ & $6 \%$ & $10.65 \%$ & $11.87 \%$ & $6 \%$ & $10.55 \%$ \\
\hline 7 & $12 \%$ & $6 \%$ & $10.68 \%$ & $11.84 \%$ & $6 \%$ & $10.55 \%$ \\
\hline
\end{tabular}

